\title{
Impact of comorbid anxiety disorders and obsessive-compulsive disorder on 24-month clinical outcomes of bipolar I disorder
}

Sung-Wan Kim ${ }^{\mathrm{a}}$, Lesley Berk ${ }^{\mathrm{b}, \mathrm{c}}$, Jayashri Kulkarni ${ }^{\mathrm{d}}$, Seetal Dodd ${ }^{\mathrm{b}, \mathrm{c}}$, Anthony de Castella ${ }^{\mathrm{d}}$, Paul B Fitzgerald ${ }^{\mathrm{d}}$, G. Paul Amminger ${ }^{\mathrm{c}, \mathrm{e}}$, Michael Berk ${ }^{\mathrm{b}, \mathrm{c}, \mathrm{e}, \mathrm{f}, *}$

${ }^{a}$ Department of Psychiatry, Chonnam National University Medical School, Gwangju, Korea.

${ }^{\mathrm{b}}$ IMPACT Strategic Research Centre, School of Medicine, Deakin University, Geelong, VIC 3220, Australia

${ }^{\mathrm{c}}$ Department of Psychiatry, University of Melbourne, Parkville, VIC 3052, Australia

${ }^{\mathrm{d}}$ Monash Alfred Psychiatry Research Centre, The Alfred Hospital and Monash University, School of Psychology and Psychiatry, Commercial Road, Melbourne VIC 3004, Australia

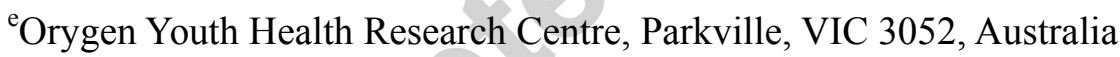

${ }_{\mathrm{f}}^{\mathrm{F}}$ lorey Institute for Neuroscience and Mental Health, Parkville, VIC 3052, Australia

*Corresponding author at: School of Medicine, Deakin University, Geelong, VIC. 3220, Australia. Tel.: +61 352267450; Fax: +61 352267436 .

E-mail: MIKEBE@BarwonHealth.org.au 


\section{Abstract}

Background: This study investigated the impact of comorbid obsessive-compulsive disorder (OCD) and four anxiety disorders [panic disorder (PD), agoraphobia, social anxiety disorder $(\mathrm{SAD})$, and generalized anxiety disorder $(\mathrm{GAD})]$ on the clinical outcomes of bipolar disorder.

Methods: This study analysed data of 174 patients with bipolar I disorder who participated in the prospective observational study. Participants were assessed every 3 months for 24 months. The primary outcome measure was the achievement of symptomatic remission, defined by a total score on the Young Mania Rating Scale (YMRS) of $\leq 12$ and a total score on the 21 -item Hamilton Depression Rating Scale (HAMD-21) of $\leq 8$.

Results: Comorbidity was associated with decreased likelihood of remission. However, the impact of individual disorders on outcome differed according to clinical and treatment situations. Most comorbid anxiety disorders and OCD had a negative effect on remission during the first year of evaluation, as measured by the HAMD-21, and in patients taking a conventional mood stabilizer alone. However, the association with poorer outcome was observed only for a few specific comorbid disorders in the second year (GAD and OCD), as measured by YMRS-defined remission (OCD), and in patients with olanzapine therapy (GAD and OCD).

Limitations: Follow-up evaluation of comorbid disorders was lacking.

Conclusions: Comorbid anxiety disorders and OCD negatively influenced the clinical course of bipolar disorder. Specifically, OCD had a consistently negative impact on the outcome of bipolar I disorder regardless of clinical situation. Effective strategies for the control of these comorbidities are required to achieve better treatment outcomes. 
Keywords: Bipolar disorder; Comorbidity; Anxiety disorder; Obsessive-compulsive disorder; Observational study; Remission 


\section{Introduction}

The diagnostic systems related to anxiety were changed in the fifth edition of the Diagnostic and Statistical Manual of Mental Disorders (DSM-5) (American Psychiatric Association). First, the DSM-5 chapter on anxiety disorders no longer includes obsessivecompulsive disorder (OCD) (which is now grouped with obsessive-compulsive and related disorders) or post-traumatic stress disorder and acute stress disorder (which are now categorised with the trauma- and stressor-related disorders). Second, panic disorder (PD) and agoraphobia are unlinked in DSM-5 because a substantial number of individuals with agoraphobia do not experience panic symptoms. Third, separation anxiety disorder and selective mutism are now classified as anxiety disorders. Finally, a new specifier, "with anxious distress," was introduced to add to the diagnosis of patients with bipolar or depressive disorder because a substantial body of research has underscored the importance of anxiety for prognosis (El-Mallakh and Hollifield, 2008) and treatment-related decisions (American Psychiatric Association). Although this anxious-distress specifier is not a distinct DSM category, it does acknowledge that anxiety is a common feature of bipolar disorder and that anxiety symptoms frequently reach the threshold of a comorbid anxiety disorder (Provencher et al., 2012).

Comorbid anxiety disorders and OCD have been reported to be common in patients with bipolar disorder. Previous studies have reported that about $30-60 \%$ of patients with bipolar disorder had at least one comorbid anxiety disorder (Corry et al., 2013). Moreover comorbid anxiety disorders and OCD are associated with greater severity, earlier age at onset, higher suicide risk, greater impulsivity, diminished acute response to pharmacological treatment, and unfavourable course and outcome of bipolar disorder (Bauer et al., 2005; 
Bellani et al., 2012; Dilsaver et al., 2006; Feske et al., 2000; Henry et al., 2003; Lee and Dunner, 2008; Simon et al., 2004, 2007; Taylor et al., 2008; Younh et al., 1993). However, most previous studies regarding the impact of comorbid disorders on clinical outcome have used a cross-sectional or retrospective design, and a few prospective studies have examined the impact of comorbid anxiety disorders, as defined by DSM criteria, on the course of bipolar disorder. Furthermore, most of these were short-term studies or included only a 1-year follow-up period (Feske et al., 2000; Otto et al., 2006).

In this study, we investigated the impact of comorbid OCD and four anxiety disorders (PD, agoraphobia, social anxiety disorder (SAD), and generalized anxiety disorder (GAD)) on the clinical course of bipolar disorder over a prospective 24-month period. For this purpose, we analysed data from the Bipolar Comprehensive Outcomes Study (BCOS) (Kulkarni et al., 2008), a 2-year, prospective, naturalistic observational study designed to improve our understanding of the treatment and outcomes of patients diagnosed with bipolar I disorder or schizoaffective disorder. 


\section{Methods}

\subsection{Study design and participants}

The rationale and design of the BCOS have been detailed previously (Berk et al., 2007; Kulkarni et al., 2008). Briefly, participants were enrolled in the study if they met the diagnostic criteria for bipolar I disorder or schizoaffective disorder, were aged 18 years or older, and were willing and able to comply with the study requirements. To obtain a representative sample of participants, the exclusion criteria were minimal. Participants could commence participation in the study at any phase of their illness. As this was an observational study, participants were not randomised to treatment groups but instead received their usual care, which could be varied by their treating clinician. At baseline, participants had to be receiving at least one of several conventional mood stabilizers (lithium carbonate, sodium valproate, or carbamazepine), olanzapine as a mood stabilizer, or a combination of a conventional mood stabilizer plus olanzapine. All treatment decisions were made by the participant's primary treating clinicians, independent of the study. Participants were recruited from October 2003 to May 2008 from Australian public hospitals and private clinics. Trained evaluators assessed participants on nine separate occasions: at study entry and every 3 months up to 24 months. All participants provided informed consent to participate in the study, which was conducted in accordance with Australian ethics and the Helsinki Declaration of 1975 and approved by the relevant ethics committees.

A total of 240 participants were enrolled in the BCOS, and 239 participants attended post-study entry visits. Of the 239 participants, 175 were diagnosed with bipolar I disorder and 64 were diagnosed with schizoaffective disorder. Data regarding participants with schizoaffective disorder were excluded from the analyses used in the present study to focus 
on the association of comorbid anxiety disorders and OCD with bipolar disorder. Of the 175 participants with bipolar disorder, one participant did not complete the MINI interview. Thus, 174 participants with bipolar disorder comprised the final study sample.

\subsection{Procedures and measures}

Diagnoses, including comorbid disorders, were confirmed by the Mini-International Neuropsychiatric Interview (MINI) version 5, a semi-structured interview designed to identify major Axis I psychiatric disorders (Sheehan et al., 1998). Current diagnosis of OCD and four anxiety disorders (PD, agoraphobia, SAD, and GAD) were selected as target comorbid disorders. Suicide risk in the past month was also measured by six questions during the MINI interview. High suicide risk was defined by scores on the relevant questions on the MINI interview.

The rate of remission over the nine evaluation points (number of remissions/9) during the 24 months was the primary outcome measure of this study. Missing data resulting from nonvisits were operationally defined as indicative of non-remission. Symptomatic remission was defined as both a Young Mania Rating Scale (YMRS) (Young et al., 1978) total score of $\leq 12$ (Lam et al., 2005) and a 21-item Hamilton Depression Rating Scale (HAMD-21) (Hamilton, 1960) total score of $\leq 8$ (Tohen et al., 2009; Kulkarni et al., 2012). Hospitalisation during the 24-month follow-up period was used as a secondary outcome variable, representing clinical course. 


\subsection{Statistical analysis}

Sociodemographic and clinical variables were compared according to comorbid disorder using independent $t$-tests, chi-square tests, or Fisher's exact tests, as appropriate. Remission rates were compared using the Mann-Whitney test according to the five comorbid disorders, gender, and type of medication. Hospitalization during the 24-month follow-up period was compared according to the above variables using chi-square tests. Remission rates were separately analysed according to pharmacologic treatment (conventional mood stabilizer alone and olanzapine \pm mood stabilizer), remission of each mood status (HAMD-21 and YMRS remission), and evaluation period (first and second year). Statistical significance was defined as $p$-values $<0.05$, and all statistical tests were two tailed. 


\section{Results}

Of the 174 participants whose data were analysed, 159 (91.4\%) completed the 24 months study. A total of $73(42.0 \%)$ met criteria for at least one of the five comorbid disorders examined in this study. Fifteen (8.7\%) met criteria for PD, 33 (19.0\%) for agoraphobia, 28 (16.1\%) for SAD, 44 (25.3\%) for GAD, and 24 (13.8\%) for OCD.

Sociodemographic and clinical characteristics at study enrolment were compared according to the presence of a comorbid disorder (Table 1). The age at onset of bipolar disorder was significantly earlier in subjects with comorbid agoraphobia, SAD, and GAD than in those without these disorders. Comorbid PD, SAD, and GAD were significantly more frequent in women than in men. Baseline HAMD-21 scores were significantly higher in patients with all comorbid disorders, but baseline YMRS scores were significantly higher only in patients with GAD and OCD.

Remission rates did not significantly differ according to gender and type of medication ( $\mathrm{p}$-value $=0.193$ and 0.659 , respectively). However, all comorbid anxiety disorders were significantly associated with lower remission rates during 24 months (Table 2). Remission rates were compared according to the presence of comorbid disorders in the first and second year separately. In the first year, all comorbid disorders were significantly associated with lower remission rates. However, in the second year, statistical significance of difference in remission rates was continued only in patients with GAD and OCD (Table 2).

The remission rates as measured by HAMD-21 and YMRS were separately compared according to the presence of each comorbid disorder (Table 2). All comorbid disorders were significantly associated with lower HAMD-21 remission rates. However, only 
OCD was significantly associated with lower YMRS remission rates.

During the 24-month period, $66(37.9 \%)$ patients were hospitalised at least once. The frequency of hospitalisation during the 24-month study period did not differ significantly according to gender, type of medication, or individual comorbid anxiety disorder (all p-values $>0.1$ ). Patients with OCD were more likely to be hospitalised during the 24-month study period than were those without OCD $(54.2 \%$ vs. $35.3 \%)$, but this difference did not reach statistical significance $(\mathrm{p}=0.077)$. Patients with any comorbid disorder at study entry were significantly more likely to be hospitalised during the follow-up period $(46.6 \%$ vs. $31.7 \%$, p $=0.046)$.

Table 3 shows comparisons of remission rates according to the presence of a comorbid disorder in patients who were treated with a conventional mood stabilizer alone and in those who were treated with olanzapine alone or in combination with other mood stabilizer. All comorbid disorders except SAD were significantly associated with lower remission rates in patients treated with a conventional mood stabilizer alone. However, only GAD and OCD were significantly associated with lower remission rates in patients treated with olanzapine \pm other mood stabilizer. 


\section{Discussion}

In this study, current comorbid anxiety disorders and OCD were common, occurring in $42 \%$ of the participants, and were associated with younger age at onset of the primary diagnosis. Comorbid anxiety disorders and OCD were associated with decreased likelihood of remission during the 2-year follow-up period. However, the impact of comorbid disorders on outcome differed according to clinical situation. Generally, the negative impact of comorbid disorders on the clinical outcome of bipolar disorder was greater during the first year than during the second year of follow up, with regard to depressive (vs. manic) symptoms, and in patients taking at baseline a conventional mood stabilizer alone (vs. olanzapine).

In many previous studies, gender differences in the prevalence of most anxiety disorders in bipolar patients were not observed (Azorin et al., 2013; Baldassano et al, 2005; Kawa et al., 2005; Krüger et al., 2000; Lee and Dunner, 2008). However, in this study, PD, $\mathrm{SAD}$ and GAD were more frequent in women than in men. In a recent study, comorbid PD, specific phobia, and OCD were more common in women with bipolar disorders than in men with bipolar disorders (Saunders et al., 2012).

The negative influence of some comorbid disorders on longitudinal outcomes for bipolar disorder disappeared as a function of time. This is a new finding from our 2-year follow-up study. Whereas the Systematic Treatment Enhancement Program for Bipolar Disorder (STEP-BD) concluded that anxiety disorders, including OCD, predicted a poorer bipolar course based on their observations during a 12-month period (Otto et al., 2006), our results suggests that the influence of some comorbid anxiety disorders on the outcome of bipolar disorder may be time limited. Improvement in comorbid disorders during the followup period may contribute to the absence of associations with decreased likelihood of 
remission in the second year, but this remains inconclusive because the MINI interview for current comorbid disorders was conducted only at baseline. Nevertheless, findings that comorbid GAD and OCD negatively influenced outcomes for at least 2 years suggest that sustained attention to these clinical conditions is needed.

Consistent with previous findings, most comorbid disorders were associated with a poorer response to lithium (Henry et al., 2003; Young et al., 1993). Moreover, in this study, comorbid GAD and OCD also showed a poorer response to olanzapine therapy. Anxiety has been shown to be an effect modifier for response to psychotherapy as well (Deckersbach et al., 2013).

All comorbid anxiety disorders and OCD were associated with higher HAMD-21 scores at baseline. This is compatible with findings that individuals with anxiety disorders or OCD are highly likely to suffer from a comorbid depressive disorder (Fineberg et al., 2005; Kessler et al., 1994). Serotonin dysfunction may be a common etiologic factor among anxiety disorders, OCD, depression, and suicidality in patients with bipolar disorder (Krüger et al., 2000). In contrast, the associations of comorbid anxiety disorders with baseline scores and remission rates on the YMRS were relatively weak. These finding suggest that more severe depressive symptoms may mediate the impact of comorbid anxiety disorders on the poorer outcomes of patients with bipolar disorder. A previous study suggested that depression, but not mania, mediates the relationship between comorbid anxiety and treatment outcome (Gaudiano et al., 2005). The anxiety symptoms accompanying bipolar disorder have been reported to primarily affect the depressive outcomes of bipolar disorders (Goldberg and Fawcett, 2012). However, in this study, comorbid GAD and OCD were associated with higher YMRS scores at baseline. Moreover, OCD was associated with lower remission rates 
of manic symptoms. A previous clinical trial in a small group of bipolar patients also showed that the anti-manic effect of olanzapine was less effective in the presence of comorbid OCD (Joshi et al., 2010). These results suggest that OCD may be associated with more severe psychopathology and poorer outcomes of manic as well as depressive symptoms.

The impact of OCD on poor outcome, regardless of evaluation time, type of medication, and mood symptoms, suggests that OCD is a particularly important comorbid condition in patients with bipolar disorder. Indeed, comorbid OCD has been reported to be associated with a poorer long-term outcome in patients with other psychotic disorders, such as schizophrenia (Hwang et al., 2009; Kim et al., 2013). From a therapeutic perspective, it is difficult to manage patients with both bipolar disorder and OCD because antidepressants, which are the treatment of choice for OCD, have been reported to induce a switch to mania or rapid cycling in bipolar patients (Perugi et al., 2002; Raja and Azzoni, 2004). Furthermore, atypical antipsychotics, which are widely used for the treatment of bipolar disorders $(\mathrm{Ng}$ et al., 2007), have been reported to induce or exacerbate obsessive-compulsive symptoms, as well as treat them (Kim et al., 2009; Matsunaga et al., 2009). This complicated treatment situation involving comorbid OCD and bipolar disorder may contribute to a poor clinical course. Psychosocial interventions, including cognitive-behavioural therapy, for these complicated patients should be developed (Provencher et al., 2011).

The negative impact of anxiety disorders on the course of bipolar disorder also suggests the need to develop interventions for comorbid anxiety disorders. However, as discussed above, antidepressants, which are the first-line treatment for anxiety disorders, are not recommended, at least as monotherapies, for patients with bipolar disorder (Pacchiarotti et al., 2013; Yatham et al., 2013). Therefore, other effective strategies for the control of 
anxiety disorders in bipolar disorder are required. Unfortunately, data from controlled studies to help guide clinicians who treat these patients are scarce (Provencher et al., 2012; Rakofsky and Dunlop, 2011). Whereas quetiapine was reported to reduce anxiety in bipolar patients with comorbid PD or GAD (Sheehan et al., 2013), risperidone was not effective in controlling anxiety in bipolar disorder (Sheehan et al., 2009). Moreover, no evidence on the impact of anxiety treatment on the improvement of the clinical course of bipolar disorder is currently available (Simon et al., 2004). Nevertheless, the high prevalence and negative impact of comorbid anxiety disorders and OCD highlight the need for greater attention to this population (Lee and Dunner, 2008) and for interventions for anxiety and obsessivecompulsive symptoms that can be integrated into management strategies for patients with bipolar disorder. Furthermore, the biological substrate of comorbid anxiety disorders and OCD in bipolar disorder should be investigated to clarify the mechanism by which these disorders achieve their negative impact and to develop effective and safe treatment strategies.

Several limitations should be considered when interpreting these data. First, followup evaluation of comorbid disorders was lacking in this study. Regular checks of comorbidity in patients with bipolar disorder would provide more information about longitudinal outcomes. Second, our study did not address the impact of the severity of anxiety and obsessive-compulsive symptoms or the impact of subsyndromal anxiety features, which have also been associated with poorer outcomes in bipolar disorder (Feske et al., 2000; Frank et al., 2002). Third, the potential impact of concomitant psychosocial therapies on the outcomes was not evaluated in this study. Fourth, HAMD-21 and YMRS scores were used to evaluate symptoms in the week prior to the assessment visit. Given the fluctuating course of symptoms, this timing may not adequately reflect the symptoms across the 3 -month interval 
between visits. However, the 2-year prospective observation period provided an extended period of observation that enabled examination of the fluctuating course of illnesses and outcomes. Finally, the sample and setting may have resulted in a selection bias and unmeasured confounding variables. However, our prospective pragmatic study design, high 2-year retention rate, and inclusion of patients at all levels of symptom severity and treatment, allows for broad generalizability (Kulkarni et al., 2012).

In conclusion, comorbid anxiety disorders and OCD negatively influence the clinical course of bipolar disorder. Given the clinical significance of comorbid anxiety disorders and OCD in bipolar disorder, routine and regular evaluations of comorbid anxiety disorders and OCD using a formal diagnostic interview are recommended. Furthermore, special attention and management strategies are required for patients with these comorbid disorders to achieve better treatment outcomes in bipolar disorders (Jones et al., 2013). 


\section{References}

American Psychiatric Association. Highlights of changes from DSM-IV to DSM-5. Available from: http://www.dsm5.org/Documents/changes\%20from\%20dsm-ivtr\%20to\%20dsm-5.pdf. Last accessed December 5, 2013.

Azorin, J.M., Belzeaux, R., Kaladjian, A., Adida, M., Hantouche, E., Lancrenon, S., Fakra, E., 2013. Risks associated with gender differences in bipolar I disorder. J. Affect. Disord. 151, 1033-1040.

Baldassano, C.F., Marangell, L.B., Gyulai, L., Ghaemi, S.N., Joffe, H., Kim, D.R., Sagduyu, K., Truman, C.J., Wisniewski, S.R., Sachs, G.S., Cohen, L.S., 2005. Gender differences in bipolar disorder: retrospective data from the first 500 STEP-BD participants. Bipolar Disord. 7, 465-470.

Bauer, M.S., Altshuler, L., Evans, D.R., Beresford, T., Williford, W.O., Hauger, R., VA Cooperative Study 430 Team. 2005. Prevalence and distinct correlates of anxiety, substance, and combined comorbidity in a multi-site public sector sample with bipolar disorder. J. Affect. Disord. 85, 301-315.

Bellani, M., Hatch, J.P., Nicoletti, M.A., Ertola, A.E., Zunta-Soares, G., Swann, A.C., Brambilla, P., Soares, J.C., 2012. Does anxiety increase impulsivity in patients with bipolar disorder or major depressive disorder? J. Psychiatr. Res. 46, 616-621.

Berk, M., Dodd, S., Callaly, P., Berk, L., Fitzgerald, P., de Castella, A.R., Filia, S., Filia, K., Tahtalian, S., Biffin, F., Kelin, K., Smith, M., Montgomery, W., Kulkarni, J., 2007. History of illness prior to a diagnosis of bipolar disorder or schizoaffective disorder. J. Affect. Disord. 103, 181-186. 
Corry, J., Green, M., Roberts, G., Frankland, A., Wright, A., Lau, P., Loo, C., Breakspear, M., Mitchell, P.B., 2013. Anxiety, stress and perfectionism in bipolar disorder. J. Affect. Disord. 151, 1016-1024.

Deckersbach, T., Peters, A.T., Sylvia, L., Urdahl, A., Magalhães, P.V., Otto, M.W., Frank, E., Miklowitz, D.J., Berk, M., Kinrys, G., Nierenberg, A., 2013. Do Comorbid Anxiety Disorders Moderate the Effects of Psychotherapy for Bipolar Disorder? Results From STEP-BD. Am. J. Psychiatry. (in press).

Dilsaver, S.C., Akiskal, H.S., Akiskal, K.K., Benazzi, F., 2006. Dose-response relationship between number of comorbid anxiety disorders in adolescent bipolar/unipolar disorders, and psychosis, suicidality, substance abuse and familiality. J. Affect. Disord. 96, 249258.

El-Mallakh, R.S., Hollifield, M., 2008. Comorbid anxiety in bipolar disorder alters treatment and prognosis. Psychiatr. Q. 79, 139-150.

Frank, E., Cyranowski, J.M., Rucci, P., Shear, M.K., Fagiolini, A., Thase, M.E., Cassano, G.B., Grochocinski, V.J., Kostelnik, B., Kupfer, D.J., 2002. Clinical significance of lifetime panic spectrum symptoms in the treatment of patients with bipolar I disorder. Arch. Gen. Psychiatry. 59, 905-911.

Feske, U., Frank, E., Mallinger, A.G., Houck, P.R., Fagiolini, A., Shear, M.K., Grochocinski, V.J., Kupfer, D.J., 2000. Anxiety as a correlate of response to the acute treatment of bipolar I disorder. Am. J. Psychiatry. 157, 956-962.

Fineberg, N.A., Fourie, H., Gale, T.M., Sivakumaran, T., 2005. Comorbid depression in obsessive compulsive disorder (OCD): symptomatic differences to major depressive 
disorder. J. Affect. Disord. 87, 327-330.

Gaudiano, B.A., Miller, I.W., 2005. Anxiety disorder comobidity in Bipolar I Disorder: relationship to depression severity and treatment outcome. Depress. Anxiety. 21, 71-77.

Goldberg, D., Fawcett, J., 2012. The importance of anxiety in both major depression and bipolar disorder. Depress. Anxiety. 29, 471-478.

Hamilton, M., 1960. A rating scale for depression. J. Neurol. Neurosurg. Psychiatry. 23, 5662.

Henry, C., Van den Bulke, D., Bellivier, F., Etain, B., Rouillon, F., Leboyer, M., 2003. Anxiety disorders in 318 bipolar patients: prevalence and impact on illness severity and response to mood stabilizer. J. Clin. Psychiatry. 64, 331-335.

Hwang, M.Y., Yum, S.Y., Kwon, J.S., 2009. Schizophrenia with obsessive compulsive features: review and clinical and conceptual issues. Clin. Psychopharmacol. Neurosci. 7, $9-14$.

Jones, S., McGrath, E., Hampshire, K., Owen, R., Riste, L., Roberts, C., Davies, L., Mayes, D., 2013. A randomised controlled trial of time limited CBT informed psychological therapy for anxiety in bipolar disorder. B.M.C. Psychiatry. 13, 54.

Joshi, G., Mick, E., Wozniak, J., Geller, D., Park, J., Strauss, S., Biederman, J., 2010. Impact of obsessive-compulsive disorder on the antimanic response to olanzapine therapy in youth with bipolar disorder. Bipolar Disord. 12:, 96-204.

Kawa, I., Carter. J.D., Joyce, P.R., Doughty, C.J., Frampton, C.M., Wells, J.E., Walsh, A.E., Olds, R.J., 2005. Gender differences in bipolar disorder: age of onset, course, 
comorbidity, and symptom presentation. Bipolar Disord. 7, 119-125.

Kessler, R.C., McGonagle, K.A., Zhao, S., Nelson, C.B., Hughes, M., Eshleman, S., Wittchen, H.U., Kendler, K.S., 1994. Lifetime and 12-month prevalence of DSM-III-R psychiatric disorders in the United States. Results from the National Comorbidity Survey. Arch. Gen. Psychiatry. 51, 8-19.

Kim, S.W., Lindenmayer, J.P., Hwang, M.Y., 2013. Schizophrenia with obsessivecompulsive symptoms: clinical and conceptual issues. Psychiatr. Ann. 43, 442-445.

Kim, S.W., Shin, I.S., Kim, J.M., Youn, T., Yang, S.J., Hwang, M.Y., Yoon, J.S., 2009. The 5-HT2 receptor profiles of antipsychotics in the pathogenesis of obsessive-compulsive symptoms in schizophrenia. Clin. Neuropharmacol. 32, 224-226.

Krüger, S., Bräunig, P., Cooke, R.G., 2000. Comorbidity of obsessive-compulsive disorder in recovered inpatients with bipolar disorder. Bipolar Disord. 2, 71-74.

Kulkarni, J., Berk, M., Fitzgerald, P.B., de Castella, A.R., Montgomery, W., Kelin, K., Brnabic, A., Granger, R.E., Dodd, S., 2008. The Bipolar Comprehensive Outcomes Study (BCOS): baseline findings of an Australian cohort study. J. Affect. Disord. 107, $135-144$.

Kulkarni, J., Filia, S., Berk, L., Filia, K., Dodd, S., de Castella, A., Brnabic, A.J., Lowry, A.J., Kelin, K., Montgomery, W., Fitzgerald, P.B., Berk, M., 2012. Treatment and outcomes of an Australian cohort of outpatients with bipolar I or schizoaffective disorder over twenty-four months: implications for clinical practice. B.M.C. Psychiatry. 12,228 .

Lam, R.W., Michalak, E.E., Swinson, R.P., 2005. Assessment Scales in Depression, Mania 
and Anxiety. Taylor and Francis, London and New York.

Lee, J.H., Dunner, D.L., 2008. The effect of anxiety disorder comorbidity on treatment resistant bipolar disorders. Depress. Anxiety. 25, 91-97.

Matsunaga, H., Nagata, T., Hayashida, K., Ohya, K., Kiriike, N., Stein, D.J., 2009. A longterm trial of the effectiveness and safety of atypical antipsychotic agents in augmenting SSRI-refractory obsessive-compulsive disorder. J. Clin. Psychiatry. 70, 863-868.

Ng, F., Dodd, S., Berk, M., 2007. Atypical antipsychotics for bipolar disorder: overblown or blown over? Clin. Psychopharmacol. Neurosci. 5, 53-64.

Otto, M.W., Simon, N.M., Wisniewski, S.R., Miklowitz, D.J., Kogan, J.N., ReillyHarrington, N.A., Frank, E., Nierenberg, A.A., Marangell, L.B., Sagduyu, K., Weiss, R.D., Miyahara, S., Thase, M.E., Sachs, G.S., Pollack, M.H.; STEP-BD Investigators., 2006. Prospective 12-month course of bipolar disorder in out-patients with and without comorbid anxiety disorders. Br. J. Psychiatry. 189, 20-25.

Pacchiarotti, I., Bond, D.J., Baldessarini, R.J., Nolen, W.A., Grunze, H., Licht, R.W., Post, R.M., Berk, M., Goodwin, G.M., Sachs, G.S., Tondo, L., Findling, R.L., Youngstrom, E.A., Tohen, M., Undurraga, J., González-Pinto, A., Goldberg, J.F., Yildiz, A., Altshuler, L.L., Calabrese, J.R., Mitchell, P.B., Thase, M.E., Koukopoulos, A., Colom, F., Frye, M.A., Malhi, G.S., Fountoulakis, K.N., Vázquez, G., Perlis, R.H., Ketter, T.A., Cassidy, F., Akiskal, H., Azorin, J.M., Valentí, M., Mazzei, D.H., Lafer, B., Kato, T., Mazzarini, L., Martínez-Aran, A., Parker, G., Souery, D., Ozerdem, A., McElroy, S.L., Girardi, P., Bauer, M., Yatham, L.N., Zarate, C.A., Nierenberg, A.A., Birmaher, B., Kanba, S., ElMallakh, R.S., Serretti, A., Rihmer, Z., Young, A.H., Kotzalidis, G.D., MacQueen, G.M., 
Bowden, C.L., Ghaemi, S.N., Lopez-Jaramillo, C., Rybakowski, J., Ha, K., Perugi, G., Kasper, S., Amsterdam, J.D., Hirschfeld, R.M., Kapczinski, F., Vieta, E., 2013. The International Society for Bipolar Disorders (ISBD) Task Force Report on Antidepressant Use in Bipolar Disorders. Am. J. Psychiatry. 170, 1249-1262.

Perugi, G., Toni, C., Frare, F., Travierso, M.C., Hantouche, E., Akiskal, H.S., 2002. Obsessive-compulsive-bipolar comorbidity: a systematic exploration of clinical features and treatment outcome. J. Clin. Psychiatry. 63, 1129-1134.

Provencher, M.D., Guimond, A.J., Hawke, L.D., 2012. Comorbid anxiety in bipolar spectrum disorders: a neglected research and treatment issue? J. Affect. Disord. 137, 161-164.

Provencher, M.D., Hawke, L.D., Thienot, E., 2011. Psychotherapies for comorbid anxiety in bipolar spectrum disorders. J. Affect. Disord. 133, 371-380.

Rakofsky, J.J., Dunlop, B.W., 2011. Treating nonspecific anxiety and anxiety disorders in patients with bipolar disorder: a review. J. Clin. Psychiatry. 72, 81-90.

Raja, M., Azzoni, A., 2004. Clinical management of obsessive-compulsive-bipolar comorbidity: a case series. Bipolar Disord. 6, 264-270.

Saunders, E.F., Fitzgerald, K.D., Zhang, P., McInnis, M.G., 2012. Clinical features of bipolar disorder comorbid with anxiety disorders differ between men and women. Depress. Anxiety. 29, 739-734.

Sheehan, D.V., Harnett-Sheehan, K., Hidalgo, R.B., Janavs, J., McElroy, S.L., Amado, D., Suppes, T., 2013. Randomized, placebo-controlled trial of quetiapine XR and divalproex ER monotherapies in the treatment of the anxious bipolar patient. J. Affect. 
Disord. 145, 83-94.

Sheehan, D.V., McElroy, S.L., Harnett-Sheehan, K., Keck, P.E. Jr., Janavs, J., Rogers, J., Gonzalez, R., Shivakumar, G., Suppes, T., 2009. Randomized, placebo-controlled trial of risperidone for acute treatment of bipolar anxiety. J. Affect. Disord. 115, 376-385.

Sheehan, D.V., Lecrubier, Y., Sheehan, K.H., Amorim, P., Janavs, J., Weiller, E., Hergueta, T., Baker, R., Dunbar, G.C., 1998. The Mini-International Neuropsychiatric Interview (M.I.N.I.): the development and validation of a structured diagnostic psychiatric interview for DSM-IV and ICD-10. J. Clin. Psychiatry. 59(Suppl 20), 22-33.

Simon, N.M., Otto, M.W., Wisniewski, S.R., Fossey, M., Sagduyu, K., Frank, E., Sachs, G.S., Nierenberg, A.A., Thase, M.E., Pollack, M.H., 2004. Anxiety disorder comorbidity in bipolar disorder patients: data from the first 500 participants in the Systematic Treatment Enhancement Program for Bipolar Disorder (STEP-BD). Am. J. Psychiatry. 161, 2222-2229.

Simon, N.M., Zalta, A.K., Otto, M.W., Ostacher, M.J., Fischmann, D., Chow, C.W., Thompson, E.H., Stevens, J.C., Demopulos, C.M., Nierenberg, A.A., Pollack, M.H., 2007. The association of comorbid anxiety disorders with suicide attempts and suicidal ideation in outpatients with bipolar disorder. J. Psychiatr. Res. 41, 255-264.

Taylor, C.T., Hirshfeld-Becker, D.R., Ostacher, M.J., Chow, C.W., LeBeau, R.T., Pollack, M.H., Nierenberg, A.A., Simon, N.M., 2008. Anxiety is associated with impulsivity in bipolar disorder. J. Anxiety. Disord. 22, 868-876.

Tohen, M., Frank, E., Bowden, C.L., Colom, F., Ghaemi, S.N., Yatham, L.N., Malhi, G.S., Calabrese, J.R., Nolen, W.A., Vieta, E., Kapczinski, F., Goodwin, G.M., Suppes, T., 
Sachs, G.S., Chengappa, K.R., Grunze, H., Mitchell, P.B., Kanba, S., Berk, M., 2009.

The International Society for Bipolar Disorders (ISBD) Task Force report on the nomenclature of course and outcome in bipolar disorders. Bipolar Disord. 11, 453-473.

Yatham, L.N., Kennedy, S.H., Parikh, S.V., Schaffer, A., Beaulieu, S., Alda, M., O'Donovan, C., Macqueen, G., McIntyre, R.S., Sharma, V., Ravindran, A., Young, L.T., Milev, R., Bond, D.J., Frey, B.N., Goldstein, B.I., Lafer, B., Birmaher, B., Ha, K., Nolen, W.A., Berk, M., 2013. Canadian Network for Mood and Anxiety Treatments (CANMAT) and International Society for Bipolar Disorders (ISBD) collaborative update of CANMAT guidelines for the management of patients with bipolar disorder: update 2013. Bipolar Disord. 15, 1-44.

Young, L.T., Cooke, R.G., Robb, J.C., Levitt, A.J., Joffe, R.T., 1993. Anxious and nonanxious bipolar disorder. J. Affect. Disord. 29, 49-52.

Young, R.C., Biggs, J.T., Ziegler, V.E., Meyer, D.A., 1978. A rating scale for mania: reliability, validity and sensitivity. Br. J. Psychiatry. 133, 429-435. 
Table 1. Sociodemographic and clinical characteristics at study entry according to the presence of a comorbid disorder

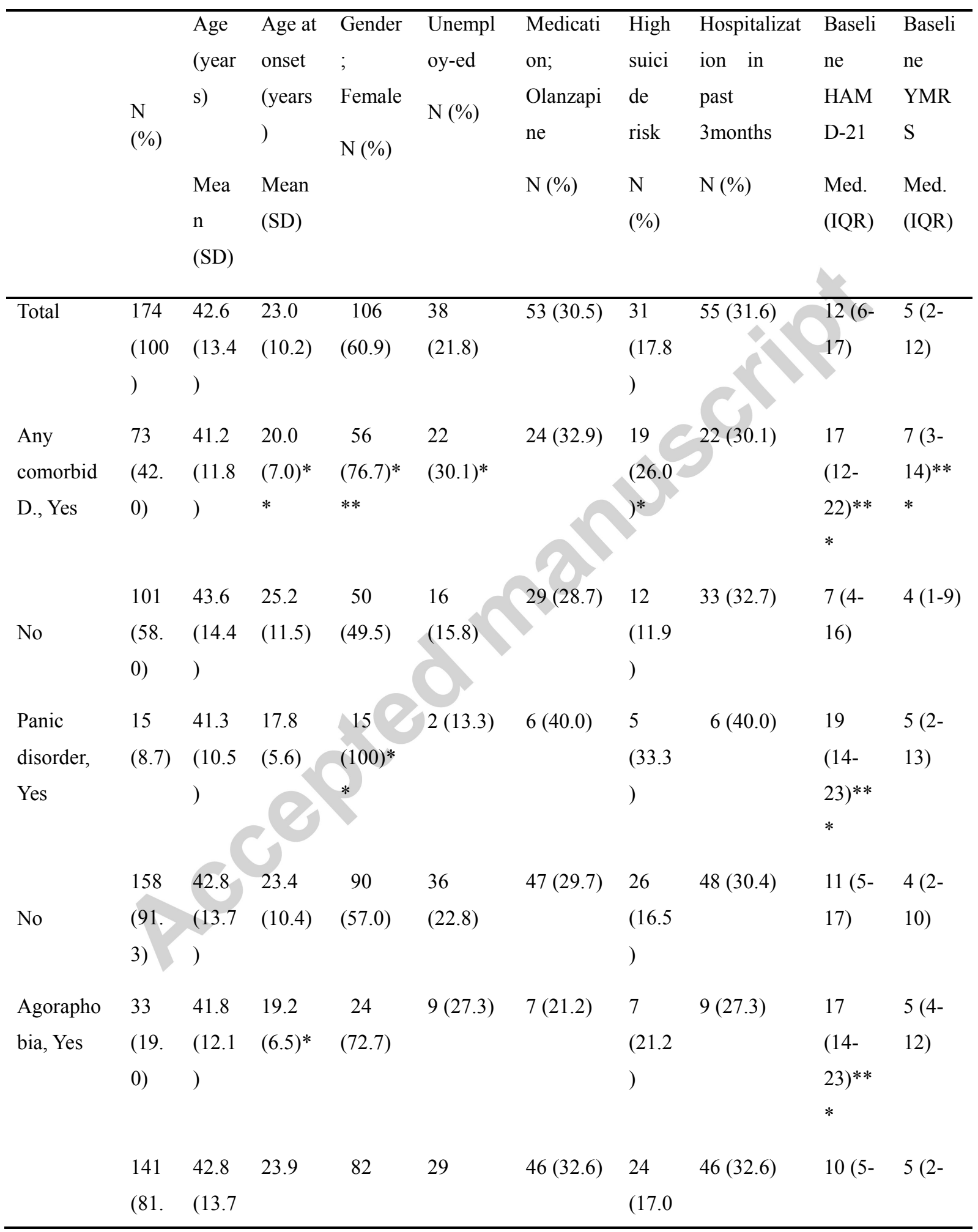




\begin{tabular}{|c|c|c|c|c|c|c|c|c|c|c|}
\hline No & 0) & ) & $(10.7)$ & $(58.2)$ & $(20.6)$ & & ) & & 16) & 13) \\
\hline \multirow[t]{3}{*}{ SAD, Yes } & 28 & 41.4 & 19.0 & 24 & 7 & $6(21.4)$ & 8 & $7(25.0)$ & 16 & $7(2-$ \\
\hline & $(16$. & $(10.4$ & $(5.7)^{*}$ & $(85.7)^{*}$ & $(25.0)$ & & $(28.6$ & & (11- & 13) \\
\hline & 1) & ) & $*$ & $*$ & & & ) & & $25)^{* *}$ & \\
\hline \multirow[t]{3}{*}{ No } & 146 & 42.8 & 23.8 & 82 & 31 & $47(32.2)$ & 23 & $48(32.9)$ & $11(5-$ & $5(2-$ \\
\hline & $(83$. & $(13.9$ & $(10.7)$ & $(56.2)$ & $(21.2)$ & & $(15.8$ & & 17) & 12) \\
\hline & 9) & ) & & & & & ) & & & \\
\hline \multirow[t]{6}{*}{ GAD, Yes } & 44 & 42.5 & 19.1 & 34 & 13 & $15(34.1)$ & 13 & $13(29.5)$ & 17 & $8(4-$ \\
\hline & $(25$. & $(11.3$ & $(6.9)^{*}$ & $(77.3)^{*}$ & $(29.5)$ & & $(29.5$ & & (12- & $14)^{*}$ \\
\hline & 3) & ) & $* *$ & & & & )$^{*}$ & & $25)^{* *}$ & \\
\hline & 130 & 42.6 & 24.4 & 72 & 25 & $38(29.2)$ & 18 & $42(32.3)$ & $10(5-$ & $5(2-$ \\
\hline & $(74$. & $(14.1$ & $(10.8)$ & $(55.4)$ & $(19.2)$ & & (13.8 & & 16) & 11) \\
\hline & 7) & ) & & & & & ) & & & \\
\hline \multirow[t]{4}{*}{ OCD, Yes } & 24 & 39.8 & 19.1 & 17 & 9 & $11(45.8)$ & 6 & $5(20.8)$ & 17 & $13(7-$ \\
\hline & (13. & $(12.0$ & $(7.0)$ & $(70.8)$ & $(37.5)^{*}$ & & $(25.0$ & & (13- & $18)^{* *}$ \\
\hline & 8) & ) & & & & & ) & & $22)^{* *}$ & $*$ \\
\hline & & & & & & & & & $*$ & \\
\hline \multirow[t]{3}{*}{ No } & 150 & 43.0 & 23.6 & 89 & 29 & $42(28.0)$ & 25 & $50(33.3)$ & $11(5-$ & $5(2-9)$ \\
\hline & $(86$. & $(13.6$ & $(10.5)$ & $(59.3)$ & (19.3) & & $(16.7$ & & 17) & \\
\hline & 2) & ) & & & & & ) & & & \\
\hline
\end{tabular}

$* \mathrm{p}<0.05, * * \mathrm{p}<0.01, * * * \mathrm{p}<0.001$

D., Disorder; SAD, Separation Anxiety Disorder; GAD, Generalized Anxiety Disorder; OCD,

Obsessive-Compulsive Disorder; HAMD-21, 21-item Hamilton Depression Rating Scale;

YMRS, Young Mania Rating Scale; SD, Standard Deviation; Med., median; IQR, interquartile range 
Table 2. Remission rates according to the presence of comorbid disorders by evaluation period and each measurement

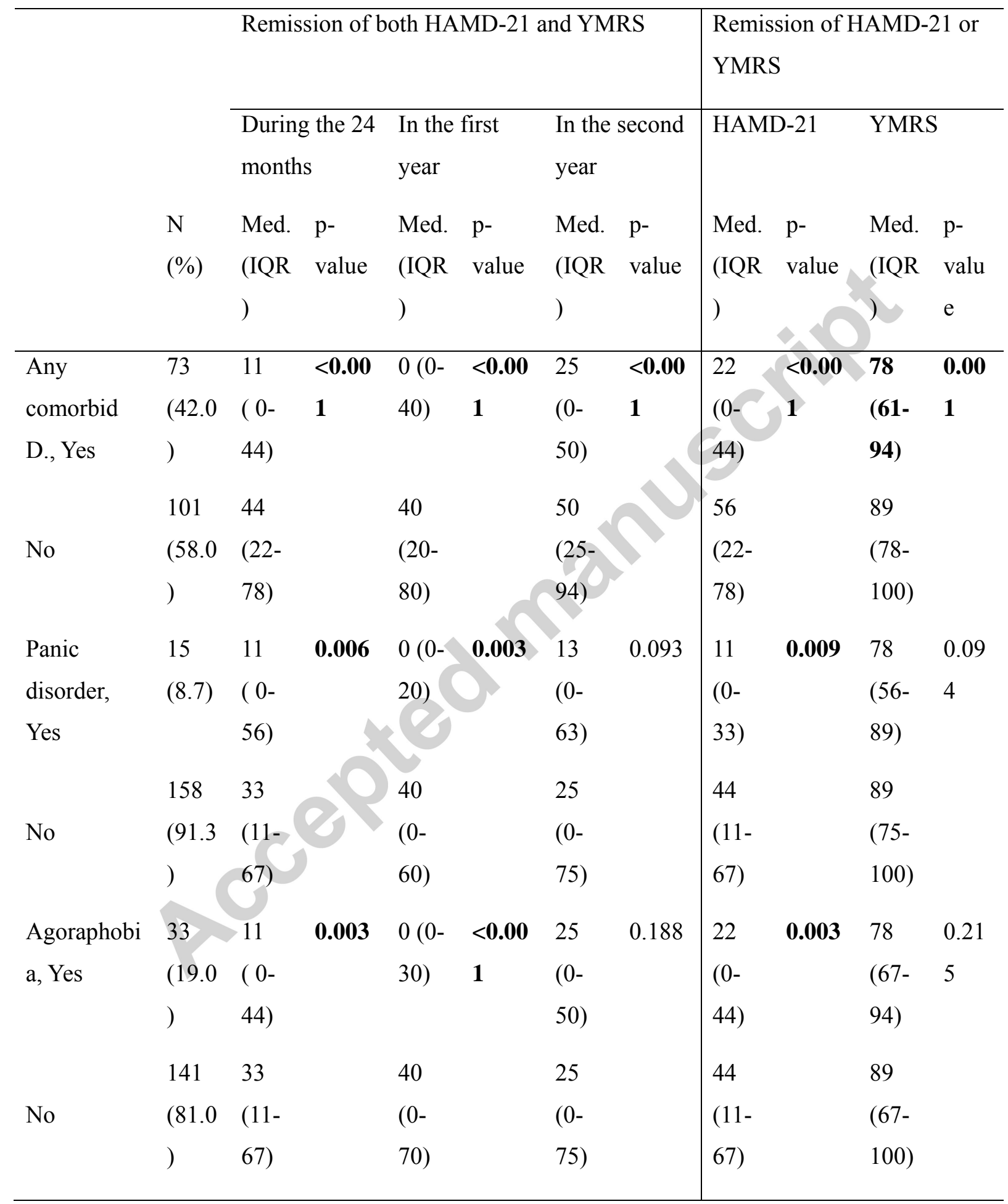




\begin{tabular}{|c|c|c|c|c|c|c|c|c|c|c|c|}
\hline \multirow[t]{3}{*}{ SAD, Yes } & 28 & 22 & 0.044 & $0(0-$ & 0.005 & 25 & 0.254 & 22 & 0.009 & 83 & 0.26 \\
\hline & (16.1 & (11- & & $35)$ & & $(0-$ & & (11- & & $(67-$ & 9 \\
\hline & ) & 42) & & & & 56) & & 44) & & 100) & \\
\hline \multirow[t]{3}{*}{ No } & 146 & 33 & & 40 & & 25 & & 44 & & 89 & \\
\hline & $(83.9$ & (11- & & $(0-$ & & $(0-$ & & (11- & & $(67-$ & \\
\hline & ) & $67)$ & & 60) & & 75) & & 67) & & 100) & \\
\hline \multirow[t]{3}{*}{ GAD, Yes } & 44 & 11 & $<0.00$ & $0(0-$ & $<0.00$ & 25 & 0.003 & 11 & $<0.00$ & 78 & 0.27 \\
\hline & $(25.3$ & $(0-$ & 1 & 40) & 1 & $(0-$ & & $(0-$ & 1 & $(67-$ & 9 \\
\hline & ) & 44) & & & & 50) & & 44) & & 100) & \\
\hline \multirow[t]{3}{*}{ No } & 130 & 44 & & 40 & & 50 & & 44 & & 89 & \\
\hline & $(74.7$ & (11- & & $(15-$ & & $(0-$ & & $(22-$ & & $(78-$ & \\
\hline & ) & $67)$ & & 80) & & 75) & & 78) & & 100) & \\
\hline \multirow[t]{3}{*}{ OCD, Yes } & 24 & 11 & 0.001 & $0(0-$ & 0.002 & 0 & 0.001 & 11 & 0.001 & 67 & 0.00 \\
\hline & $(13.8$ & $(0-$ & & 20) & & $(0-$ & & $(0-$ & & $(44-$ & 6 \\
\hline & ) & 31) & & & & 25) & & 33) & & 89) & \\
\hline \multirow[t]{3}{*}{ No } & 150 & 33 & & 40 & & 50 & & 44 & & 89 & \\
\hline & $(86.2$ & (11- & & $(0-$ & & $(0-$ & & (11- & & $(78-$ & \\
\hline & ) & 67) & & 60) & & 75) & & 67) & & 100) & \\
\hline
\end{tabular}

D., Disorder; SAD, Separation Anxiety Disorder; GAD, Generalized Anxiety Disorder; OCD, Obsessive-Compulsive Disorder; HAMD-21, 21-item Hamilton Depression Rating Scale; YMRS, Young Mania Rating Scale; Med., median; IQR, interquartile range 
Table 3. Remission rates according to the presence of a comorbid disorder in patients treated with a conventional mood stabilizer alone and in those treated with olanzapine

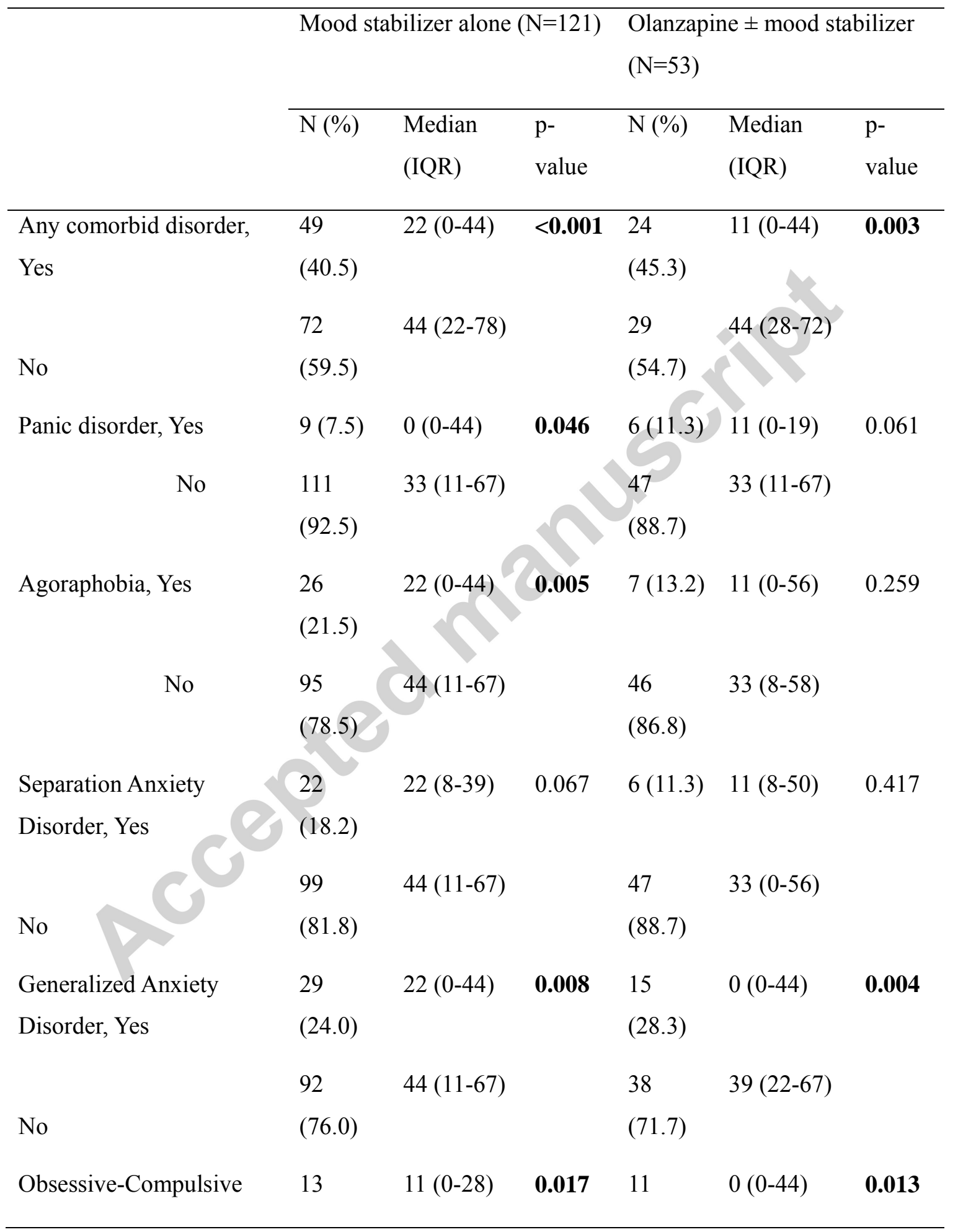




\begin{tabular}{|c|c|c|c|c|}
\hline \multirow[t]{2}{*}{ Disorder, Yes } & \multicolumn{2}{|c|}{$(10.7)$} & \multicolumn{2}{|c|}{$(20.8)$} \\
\hline & 108 & $39(11-67)$ & 42 & $33(11-67)$ \\
\hline No & $(89.3$ & & $(79$ & \\
\hline
\end{tabular}

$\mathrm{IQR}$, interquartile range

\section{Role of funding source}

The Bipolar Comprehensive Outcomes Study (BCOS) was funded by an unconditional research grant provided by Eli Lilly Australia. Lilly had no role in in the collection, analysis, interpretation of data, the writing of the report, and in the decision to submit the paper for publication.

\section{Contributors}

SWK conducted statistical analysis and wrote the first draft of the manuscript. LB was involved in conducting the assessments with participants and editing the manuscript. JK was a principle investigator on the study and was involved in editing the manuscript. SD was involved in study design and management, and editing the manuscript. AC was involved in the design and conduct of the study. PBF contributed to the overall study design and review of this manuscript. PGA was involved in the data interpretation and editing the manuscript. MB was a principle investigator on the study and was involved in editing the manuscript. All authors contributed to and have approved the final manuscript. 


\section{Potential conflicts of interest}

$\mathrm{JK}, \mathrm{SD}, \mathrm{ADC}, \mathrm{PBF}$, and $\mathrm{MB}$ have received research funding and/or speaker's fees and/or funding to attend conferences from Eli Lilly. SD has received grant from Servier. PBF has received equipment for research from MagVenture A/S, Medtronic Ltd, Cervel Neurotech and Brainsway Ltd and funding for research from Cervel Neurotech. MB has received grant/research support from the NIH, Cooperative Research Centre, Simons Autism Foundation, Cancer Council of Victoria, Stanley Medical Research Foundation, MBF, NHMRC, Beyond Blue, Rotary Health, Geelong Medical Research Foundation, Bristol Myers Squibb, Eli Lilly, Glaxo SmithKline, Meat and Livestock Board, Organon, Novartis, Mayne Pharma, Servier and Woolworths, has been a speaker for Astra Zeneca, Bristol Myers Squibb, Eli Lilly, Glaxo SmithKline, Janssen Cilag, Lundbeck, Merck, Pfizer, Sanofi Synthelabo, Servier, Solvay and Wyeth, and served as a consultant to Astra Zeneca, Bristol Myers Squibb, Eli Lilly, Glaxo SmithKline, Janssen Cilag, Lundbeck, Merck and Servier. 


\section{Acknowledgements}

The authors gratefully acknowledge the participation of the patients and investigators in the BCOS observational study. SWK is supported by Research Institute of Medical Sciences, Chonnam National University, Korea. PBF is supported by a NHMRC Practitioner Fellowship (606907). PGA is supported by NHMRC program grant 566529. MB is supported by a NHMRC Senior Principal Research Fellowship 


\section{University Library}

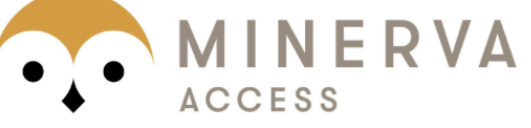

A gateway to Melbourne's research publications

Minerva Access is the Institutional Repository of The University of Melbourne

Author/s:

Kim, S-W;Berk, L;Kulkarni, J;Dodd, S;de Castella, A;Fitzgerald, PB;Amminger, GP;Berk, M

Title:

Impact of comorbid anxiety disorders and obsessive-compulsive disorder on 24-month clinical outcomes of bipolar I disorder

Date:

2014-09-01

\section{Citation:}

Kim, S. -W., Berk, L., Kulkarni, J., Dodd, S., de Castella, A., Fitzgerald, P. B., Amminger, G. P. \& Berk, M. (2014). Impact of comorbid anxiety disorders and obsessive-compulsive disorder on 24-month clinical outcomes of bipolar I disorder. JOURNAL OF AFFECTIVE DISORDERS, 166, pp.243-248. https://doi.org/10.1016/j.jad.2014.05.017.

Publication Status:

Accepted manuscript

Persistent Link:

http://hdl.handle.net/11343/41828 